\title{
Sequence of protein expression of bone sialoprotein and osteopontin at the developing interface between repair cementum and dentin in human deciduous teeth
}

Received: 14 September 2004 / Accepted: 21 February 2005 / Published online: 22 April 2005

(C) Springer-Verlag 2005

\begin{abstract}
Experimental periodontal regeneration studies have revealed the weak binding of repair cementum to the root surface, whereas attachment of cementum to dentin preconditioned by odontoclasts appears to be superior. The aim of this study has been, therefore, to analyze the structural and partial biochemical nature of the interface that develops between resorbed dentin and repair cementum by using human deciduous teeth as a model. Aldehyde-fixed and decalcified tooth samples were embedded in acrylic or epoxy resins and sectioned for light and transmission electron microscopy. Antibodies against bone sialoprotein (BSP) and osteopontin (OPN), two noncollagenous proteins accumulating at hard tissue interfaces in bone and teeth, were used for protein A-gold immunocytochemistry. Light microscopy revealed a gradually increasing staining intensity of the external dentin matrix starting after the withdrawal of the odontoclast. Labeling for both BSP and OPN was first detected among the exposed collagen fibrils and in the intratubular dentin matrix when odontoclasts had withdrawn but mesenchymal cells were present. Subsequently, collagen fibrils of the repair cementum were deposited concom-
\end{abstract}

This study was supported by the Clinical Research Foundation (CRF) for the Promotion of Oral Health, University of Berne, Berne, Switzerland.

D. D. Bosshardt $(\bowtie) \cdot$ T. Degen $\cdot$ N. P. Lang

Department of Periodontology and Fixed Prosthodontics, School of Dental Medicine,

University of Berne,

Freiburgstrasse 7,

3010 Berne, Switzerland

e-mail: dieter.bosshardt@zmk.unibe.ch

Tel.: +41-31-6328605

Fax: +41-31-6324931

T. Degen

Clinic for Oral Surgery,

Center for Dental and Oral Medicine

and Cranio-Maxillofacial Surgery,

University of Zurich,

Zurich, Switzerland itantly with the appearance of labeling for BSP and OPN over the intratubular, intertubular, and peritubular dentin matrix. Labeled mineralization foci indicated the advancing mineralization front, and the collagenous repair matrix became integrated in an electron-dense organic material that showed labeling for BSP and OPN. Thus, no distinct planar interfacial matrix layer lies between the resorbed dentin and the repair cementum. The results suggest that odontoclasts precondition the dentin matrix such that the repair cementum becomes firmly attached.

Keywords Interface - Dentin - Repair cementum - BSP . OPN $\cdot$ Human

\section{Introduction}

Mineralized connective tissues are biological composites that provide rigid structural support and mechanical protection. Interfaces in mineralized tissues are critical regions, because stress transfer occurs at these sites. Since structure and composition determine function, a knowledge of the structure-function relationships of matrix interfaces is fundamental in order to develop more predictable regenerative therapies aimed at substituting pathologically altered mineralized tissues. The problem of regeneration is impressively exemplified in teeth destroyed by periodontitis, an infectious disease that results in the loss of tooth attachment (Reynolds and Meikle 1997). Therapeutic interventions lead to a wide range of outcomes, and periodontal regeneration has been claimed not to be achieved in the true sense of the term (Schroeder 1992). The major biological problems are physical and chemical alterations of the root surface; these changes are incompatible with mesenchymal cellmatrix interactions (i.e., cell attachment, spreading, and differentiation) and impair matrix-matrix adhesion (Schroeder 1992). A crucial event is the new formation of root cementum and its adherence to the pathologically altered and treated root surface. Cementum is the mineralized tissue that covers the root dentin and invests the principal periodontal ligament fibers that connect and attach the root to the 
surrounding alveolar bone; it is, thus, indispensable for normal tooth functioning. Histology suggests weak interfacial bonding between the treated root surface and the newly formed cementum following various regenerative procedures (Schroeder 1992; Blomlöf and Lindskog 1994; Luder and Zappa 1998; Sculean et al. 1999). Although commonly attributed to histological processing, interfacial tissue separation can also have other causes (Bosshardt et al. 2005).

The structural and molecular factors contributing to interfacial mechanical resistance on treated and otherwise modified root surfaces have not been determined. Variables such as mechanical, chemical, and/or biochemical factors and the wound environment itself may all unpredictably influence the structural outcome, and consequently, the biomechanical properties. Therefore, such periodontal models may not be considered as ideal for analyzing the structurefunction relationship of tissue interfaces in teeth. In contrast, the development of the interface between repair cementum and resorbed dentin is under biological control and is less influenced by unpredictable variables (Kawaguchi et al. 2001). A further advantage is that repair cementum formation in human deciduous teeth is predictable (Sahara 1998; Sahara et al. 1993). Furthermore, the absence of tissue separation between the resorbed dentin and the repair cementum in histological sections suggests that tissue adherence is superior when root resorption precedes the deposition of a mineralized tissue (Schroeder 1992; Bosshardt and Schroeder 1994). The root surface preconditioned by odontoclasts may not only facilitate cell attachment and differentiation, but also provide a superior substrate for matrix-matrix adhesion. The aim of the present study has therefore been to analyze the nature of the attachment mechanism between resorbed dentin and repair cementum in human deciduous teeth. Since bone sialoprotein (BSP) and osteopontin (OPN) are two noncollagenous proteins (NCPs) predominantly accumulating at tissue interfaces in bone and teeth (Bosshardt et al. 1998; Nanci 1999), and since OPN is implicated as being an interfacial adhesion molecule (McKee and Nanci 1996b), we have applied high resolution immunocytochemistry with antibodies against these two NCPs.

\section{Materials and methods}

Fifteen human deciduous teeth from 13 girls and two boys with a mean age of 12 years and 4 months (minimum and maximum ages of 8 and 13.5 years, respectively) were collected for this study at the Department of Operative, Preventive and Pediatric Dentistry, School of Dental Medicine, University of Berne, Berne, Switzerland, and in a private practice. All teeth were in the final stage of resorption. Reasons for tooth extraction were delayed exfoliation or orthodontic tooth movement. Teeth exhibiting carious lesions affecting the pulp tissue were excluded from the study. Furthermore, the marginal tooth regions, which often show ingress of inflammatory cells (Sahara 1998), were not included in the analysis.
Tissue processing for light and transmission electron microscopy

Immediately after extraction, the teeth were fixed for $24 \mathrm{~h}$ at $4^{\circ} \mathrm{C}$ by immersion in $1 \%$ glutaraldehyde, $1 \%$ formaldehyde buffered with $0.08 \mathrm{M}$ sodium cacodylate ( $\mathrm{pH}$ 7.4). After decalcification in $4.13 \%$ disodium ethylenediamine tetraacetic acid (EDTA) for 4-6 weeks at $4^{\circ} \mathrm{C}$ (Warshawsky and Moore 1967), the partially demineralized teeth were subdivided into 145 thin slices oriented perpendicularly to the excavated dentin. Following extensive washes in $0.1 \mathrm{M}$ sodium cacodylate buffer containing 5\% sucrose, $\mathrm{pH} 7.3$, some tissue samples were postfixed with potassium-ferrocyanide-reduced osmium tetroxide (Neiss 1984). Osmicated samples were processed for embedding in Taab 812 epoxy resin (Merck, Dietikon, Switzerland), whereas osmicated and unosmicated samples were processed for embedding in LR White resin (Fluka, Buchs, Switzerland). Semithin survey sections $(1 \mu \mathrm{m}$ thick) were cut with glass and diamond knives on a Reichert Ultracut E microtome (Leica Microsystems, Glattbrugg, Switzerland), stained with toluidine blue, and observed in a Leica Dialux 22 EB microscope. Thin $(80-100 \mathrm{~nm})$ sections were cut with a diamond knife, contrasted with uranyl acetate and lead citrate, and examined in a Philips 300 transmission electron microscope operated at an accelerating voltage of $60 \mathrm{kV}$.

\section{Immunocytochemistry}

The high-resolution protein A-gold technique (Bendayan 1995) was used for the immunocytochemical localization of BSP and OPN. All incubations were performed at room temperature. Thin sections of LR White-embedded tissues were mounted on formvar- and carbon-coated nickel grids. Osmicated tissue sections were first treated with a saturated solution of sodium metaperiodate (Bendayan and Zollinger 1983) for $15 \mathrm{~min}$ and washed with distilled water. They were then floated on a drop of $0.01 \mathrm{M}$ phosphate-buffered saline (PBS), $\mathrm{pH} 7.3$, containing 1\% ovalbumin (Fluka) in order to saturate non-specific binding sites. Sections were transferred and incubated for $1 \mathrm{~h}$ on a drop of one of the following primary antibodies: rabbit anti-human bone sialoprotein (Chemicon, Juro, Lucerne, Switzerland), rabbit anti-human bone sialoprotein (LF-6), rabbit anti-human osteopontin (LF-7), or rabbit anti-human osteopontin (LF123). The LF-6, LF-7, and LF-123 antibodies were courtesy of Dr. L.W. Fisher, National Institutes of Health, Bethesda, Md., USA) (Fisher et al. 1995). All antibodies were diluted 1:20 with PBS. The grids were then rinsed with PBS, floated on PBS containing $1 \%$ ovalbumin for $10 \mathrm{~min}$, incubated for 30 min with protein A-gold complex prepared with gold particles of approximately 10 or $14 \mathrm{~nm}$ (Drs. G. Posthuma and J.W. Slots, University Medical Center Utrecht, Utrecht, The Netherlands), and washed with PBS and distilled water. The sections were subsequently contrasted as described above for transmission electron microscope analysis. As negative 
controls, sections were incubated with protein A-gold alone, nonimmune serum, or unrelated anti-IgG antibodies. The differential labeling patterns obtained with the two antibodies in the control tissues, viz., alveolar bone, dentin, and the various root cementum types, including the bone-bone (i.e., cement line) and the dentin-cementum interfaces, served as internal positive controls. All these control tissues were from humans and processed in the same way as the deciduous teeth.

\section{Results}

In the teeth investigated, regions with ongoing resorptive activity, arrest of resorptive activity, and various stages of new cementum formation were observed in the crown dentin. Thus, the material collected allowed us to analyze the complete sequence of repair tissue formation. No separation of the newly formed cementum layer from the dentin matrix was observed in any of the tissue sections.

\section{Light microscopy}

When odontoclasts were present in Howship's lacunae, the resorbed dentin matrix and the opened dentinal tubules revealed the same staining intensity, both in the superficial and in the deeper portions of the dentin (Fig. 1a). In the absence of odontoclasts, mononuclear cells lined the resorbed dentin surface (Fig. 1b, c). When multinucleated cells were in the vicinity of the resorbed dentin matrix, the periphery of the superficial portion of a few dentinal tubules revealed a slightly increased staining intensity (Fig. 1b). The number and staining intensity of the superficial portion of the dentinal tubules was higher when no multinucleated cells were present (Fig. 1c). In addition, a thin superficial band of moderately stained intertubular dentin was discernible at a few locations (Fig. 1c). When the deposition of repair tissue, referred to here as repair cementum, had started, the majority of dentinal tubules were intensely stained near the dentin surface, and a moderately stained band of superficial dentin matrix was consistently observed (Fig. 1d). The staining intensity of this band diminished gradually toward
Fig. 1 Crown dentin $(D)$ region of human deciduous teeth at various stages of resorption and repair ( $E F$ extrinsic fibers, $M N C$ multinucleated cells). a In the presence of odontoclasts $(O C)$, the dentin matrix at the site of resorption reveals the same staining intensity as in the deeper portions. b After the withdrawal of the odontoclasts, mononuclear cells, presumably cementoblasts, line the resorbed dentin surface, and the superficial portion of a few dentinal tubules reveals a slightly increased staining intensity (arrowheads). c The number of stained dentinal tubules and their staining intensity has increased (arrowheads). In addition, a thin superficial band of moderately stained intertubular dentin matrix is seen at some sites (arrow). d At the onset of precementum $(P C)$ deposition, the majority of dentinal tubules is intensely stained near the dentin surface, and a moderately stained band of intertubular dentin matrix is present (arrowheads).
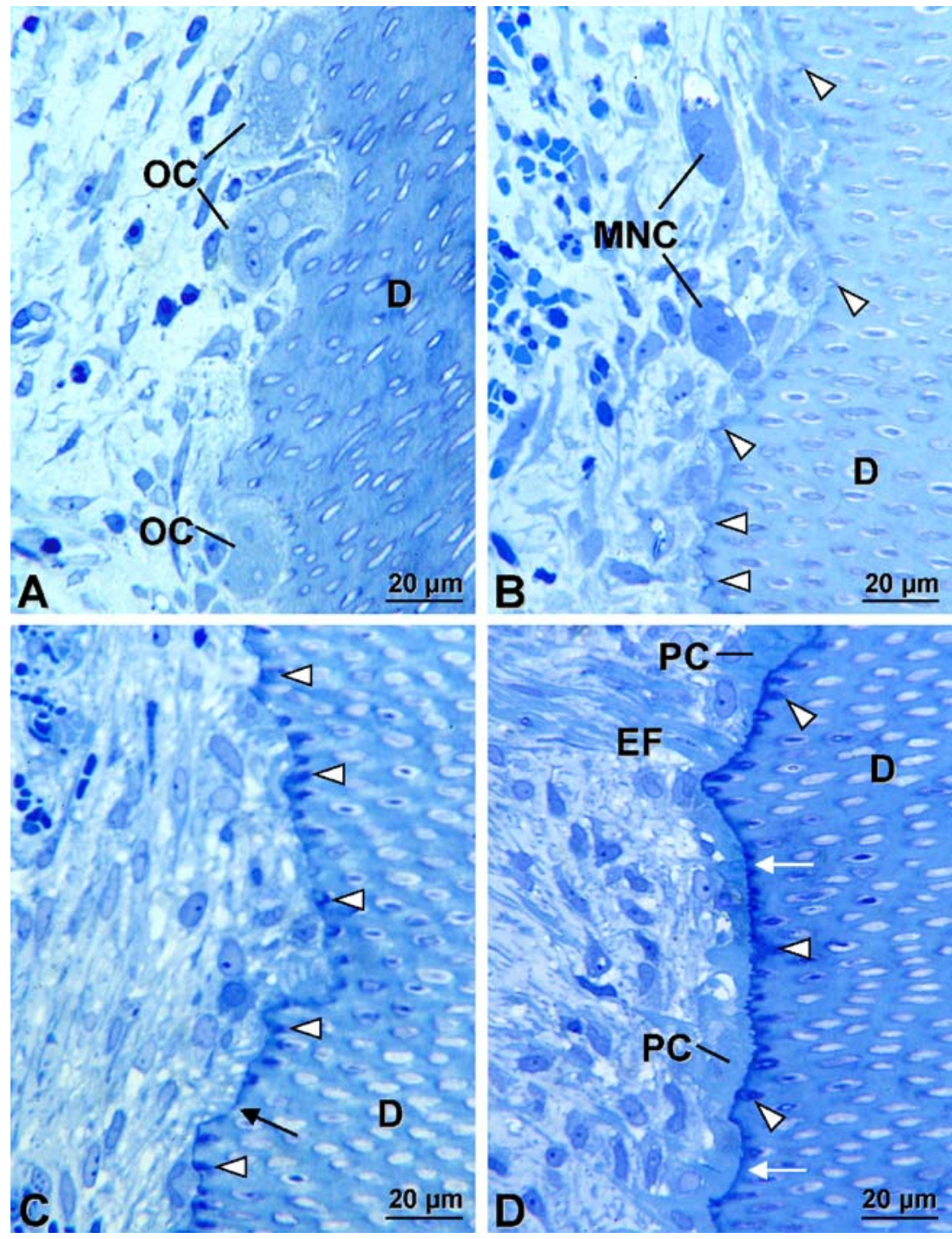
Fig. 2 Advanced stages of repair cementum formation. a The resorbed dentin is covered with a precementum $(P C)$ layer. The superficial portion of the intertubular dentin forms now a continuous band (arrows). This band and the superficial portion of the intratubular dentin matrix

(arrowheads) are prominent against both the rest of the dentin $(D)$ matrix and the precementum layer. $\mathbf{b}$ The cementum thickness has increased and a mineralization front $(M F)$ demarcates the mineralized portion of the cementum $(M C)$ from the precementum $(P C)$ layer. Intense blue staining can be seen in the intertubular (arrows) and peritubular (arrowheads) dentin matrix

Fig. 3 Immunocytochemical staining with the anti-BSP antibody (ITD intertubular dentin matrix). Odontoclasts $(O C)$ in contact with the dentin $(D)$ matrix possess a typical ruffled border $(R B)$. The resorbed dentin surface consists of protruding and exposed (i.e., demineralized) collagen fibrils ( $C F$, arrowheads). Note that there is neither an electron-dense matrix layer nor any gold particle labeling evident in association with the exposed collagen fibrils, the underlying dentin matrix, or the dentinal tubules $(D T)$.

Fig. 4 Transmission electron micrographs showing immunolabeling for OPN after the withdrawal of the odontoclasts. a The boxed area outlined is shown at higher magnification in $\mathbf{b}$. Mononuclear cells, presumably pre-cementoblasts $(C B)$, line the resorbed dentin $(D)$ surface. Although a seam of exposed dentin collagen fibrils (stars) is still discernible, no electrondense matrix layer and no gold particle labeling for OPN are observed (DT dentinal tubules, $\mathrm{Nu}$ nucleus)
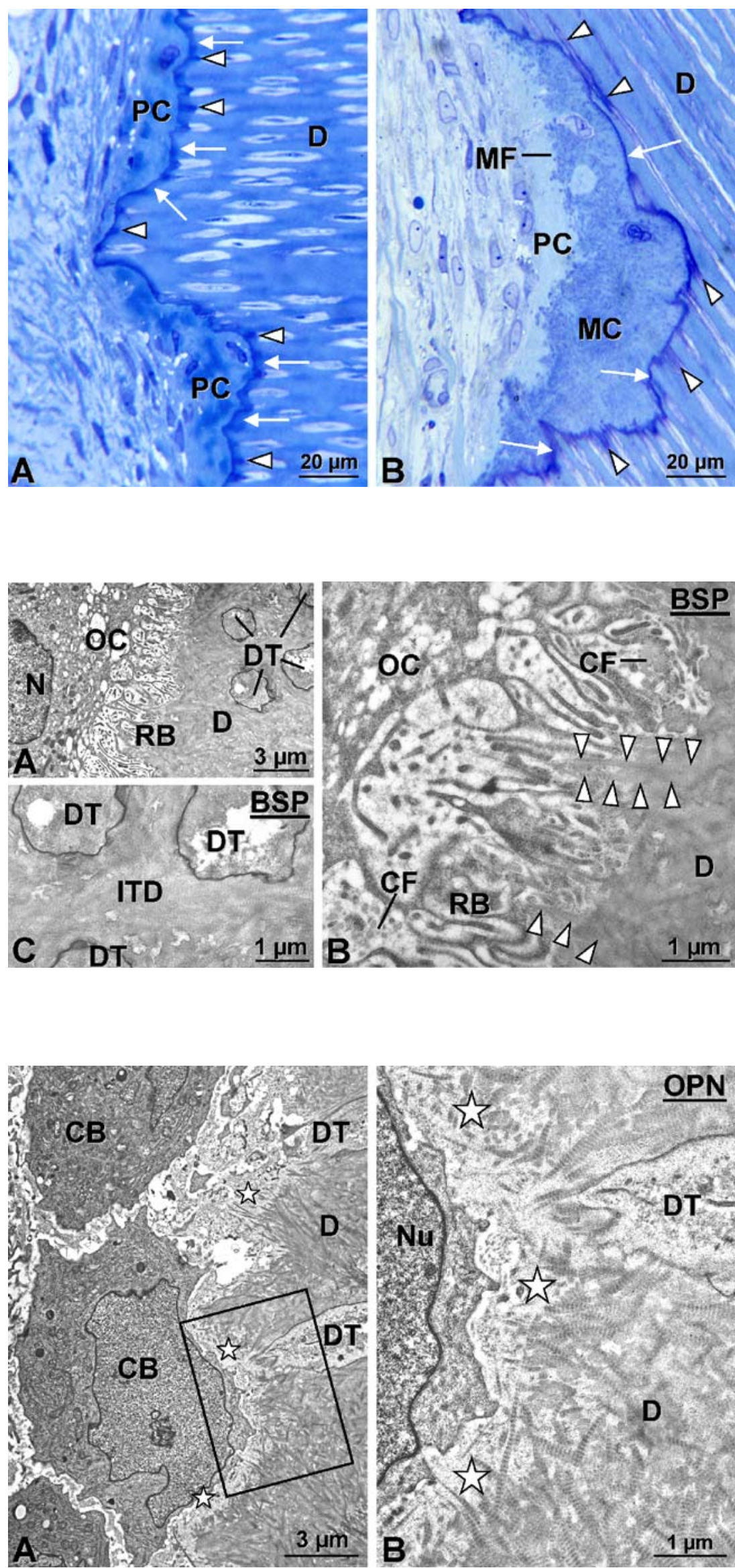
the deeper portions of the dentin. The basophilic superficial dentin band was prominent against the surrounding tissues before (Fig. 2a) and after (Fig. 2b) the cementum matrix started to mineralize, and its thickness slightly varied from one sample to another (compare Fig. 2a, b).

\section{Ultrastructure and immunocytochemistry}

All antibodies used yielded a similar labeling pattern in the region of the developing interface. The labeling intensities (i.e., number of gold particles per unit area) of the LF-6 and LF-7 antibodies were slightly above those of the two other antibodies. In all cases, sections incubated under negative control conditions showed only a few, randomly distributed, gold particles. For all antibodies used, the matrices of the control tissues, viz., dentin, acellular extrinsic fiber cementum, cellular intrinsic fiber cementum, alveolar bone, and their corresponding tissue interfaces (i.e., the dentinocemental junction in teeth and the cement line in bone), revealed a labeling pattern identical with that known from other studies (Riminucci et al. 1995; Bosshardt et al. 1998; Nanci 1999).

The dentin matrix subjacent to odontoclasts was devoid of a superficial electron-dense matrix layer (Fig. 3a) but consisted of exposed collagen fibrils protruding from the deeper mineralized portion of the dentin (Fig. 3b). Incubations with antibodies against OPN (not shown) and BSP

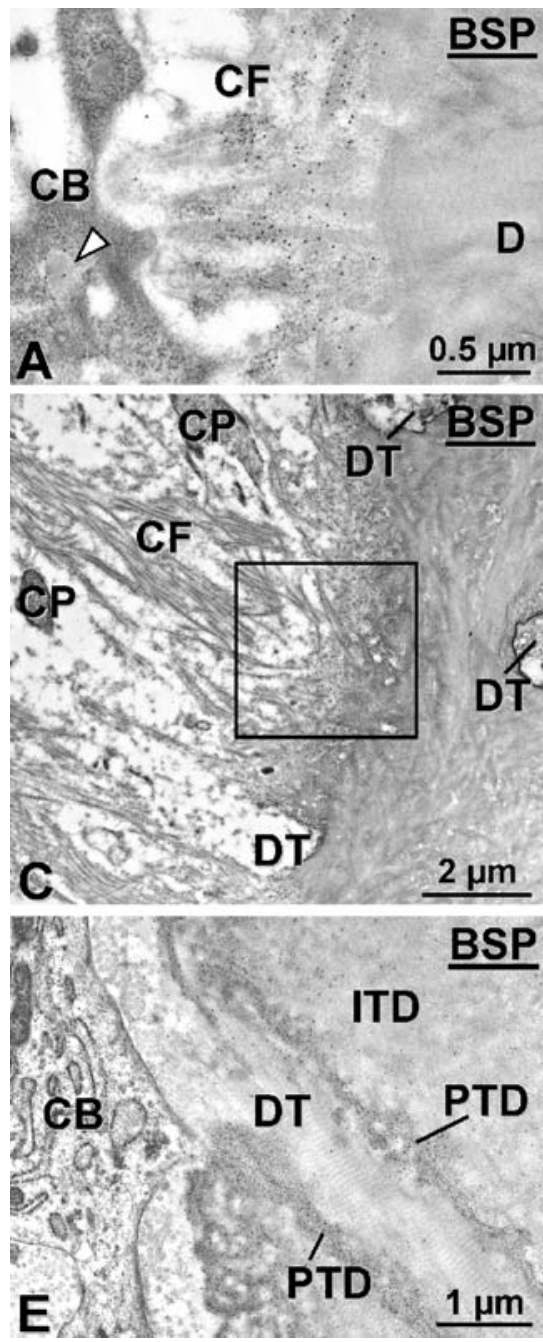

Fig. 5 Transmission electron micrographs showing various initial developmental stages of the interfacial region between repair cementum and resorbed dentin $(D)$. Incubations with antibodies against BSP (a-e) and OPN (f) gave identical results. a Immunolabeling is first seen in association with the exposed dentin collagen fibrils $(C F)$, indicating the initial development of the dentin-cementum interface. Secretory granules weakly labeled for BSP (arrowhead) are occasionally found in the cytoplasm of the adjacent cells $(C B$ cementoblast). b Labeled mineralization foci (arrowheads) revealing a similar texture and electron density as the labeled organic material that accumulated among the exposed collagen fibrils are frequently observed.

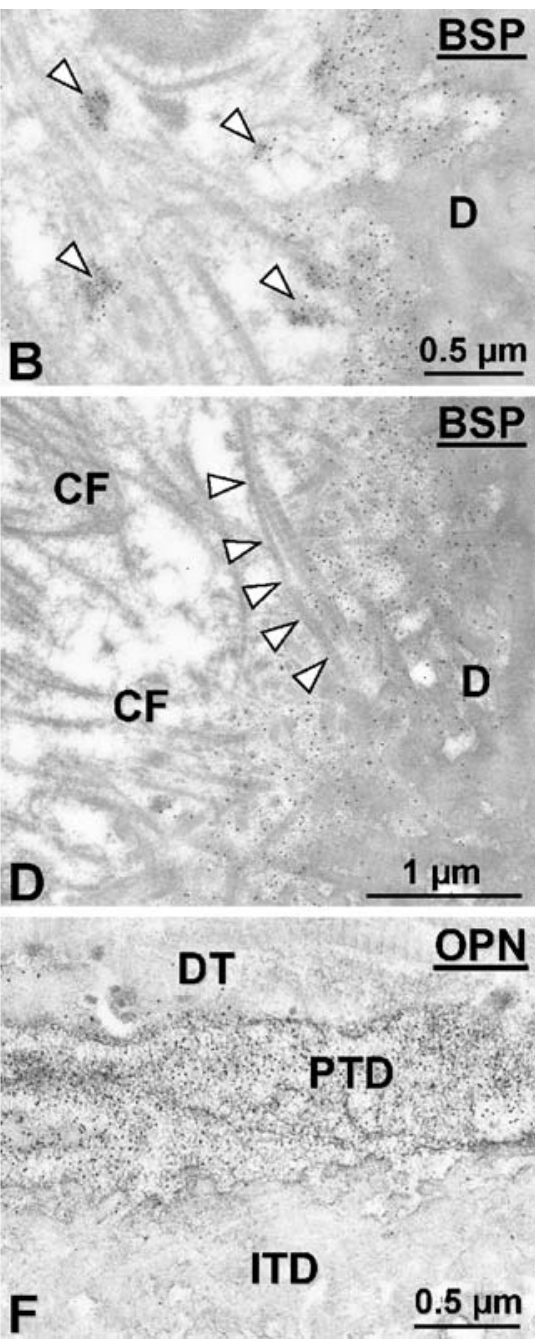

c, $\mathbf{d}$ When newly deposited collagen fibrils are evident, labeling is still restricted to the exposed dentinal matrix fibrils. The collagen fibril diameter is greater in the dentin matrix (arrowheads) than in the matrix of the repair tissue. The interfacial region consists of large interfibrillar spaces ( $C P$ cytoplasmic process, $D T$ dentinal tubules). e, f When the exposed dentin matrix is heavily obscured by electron-dense organic material, the large interfibrillar spaces are no longer discernible. Gold particles are associated with the obscured matrix at the dentin surface and the peritubular dentin $(P T D)$. The intertubular dentin matrix (ITP) in the deeper portions of dentin lacks gold particle labeling. 
(Fig. 3b, c) showed that the exposed collagen fibrils and both the intertubular and the peritubular dentin matrices were devoid of gold particles. The lumen of the dentinal tubules was often partly filled with collagen fibrils and also lacked immunolabeling (Fig. 3c). In the absence of odontoclasts, mononuclear cells lined the resorbed dentin matrix, and the seam of exposed dentinal collagen fibrils was still discernible (Fig. 4a, b). Immunolabeling for BSP (not shown) and OPN (Fig. 4b) was not observed in any of the dentin compartments in this situation. Gold particle labeling for both BSP (Fig. 5a) and OPN (not shown) was first discernible in association with the exposed dentinal collagen fibrils and concomitantly also in the peripheral portion of the intratubular dentin matrix (not shown). Labeling for BSP was occasionally found in secretory granules (Fig. 5a). Round matrix patches labeled for both BSP and OPN and revealing a similar texture and electron density as the labeled organic material that accumulated among the exposed collagen fibrils were frequently observed (Fig. 5b). When newly deposited collagen fibrils were evident (Fig. 5c), labeling was still restricted to the exposed dentinal matrix fibrils (Fig. 5d). The structure of the interfacial region was only slightly obscured

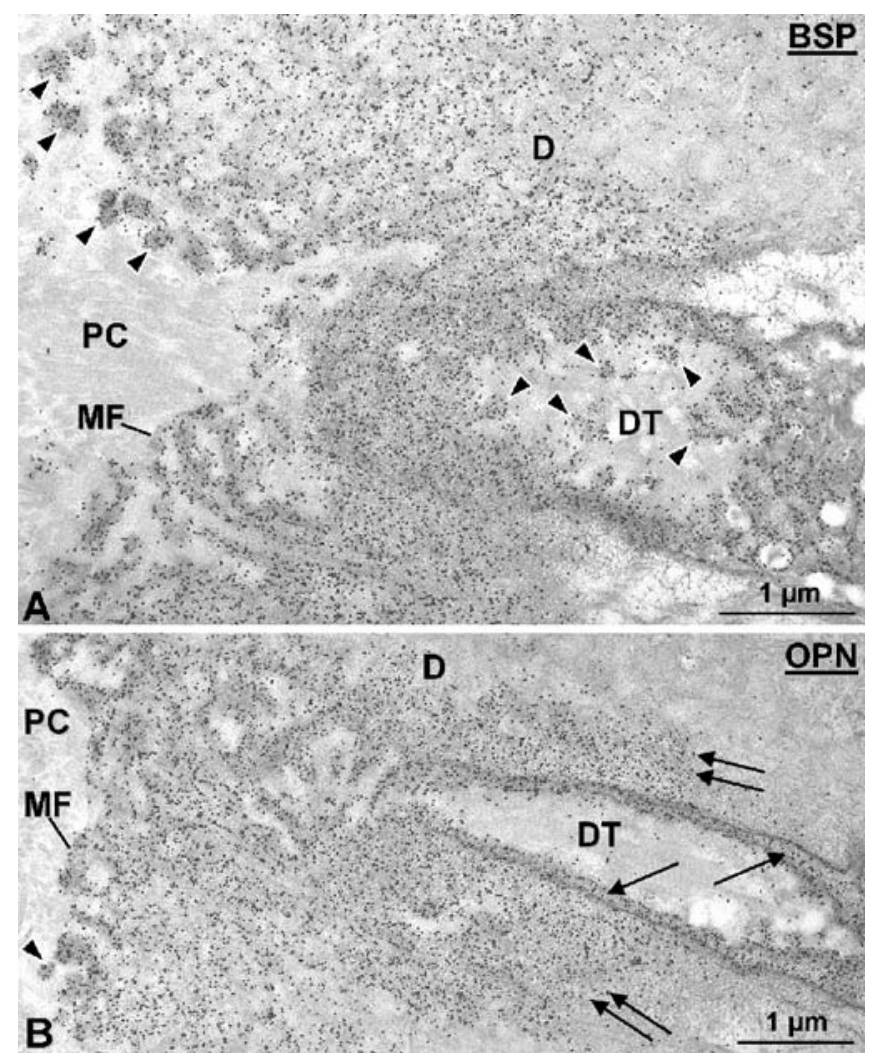

Fig. 6 Transmission electron micrographs illustrating advanced stages of repair cementum formation after incubations with antibodies against BSP (a) and OPN (b). Immunolabeling is seen adjacent to the mineralization front $(M F)$ over mineralization foci (arrowheads) and over the dentin $(D)$ matrix subjacent to the resorbed surface $(P C$ precementum). Labeling extends over the dentin matrix with a gradual decrease in the number of gold particles toward the deeper portions of the dentin matrix. Gold particles are also present internal (arrows) and external (double-arrows) to the wall of the dentinal tubules $(D T)$. and revealed large interfibrillar spaces. The collagen fibril diameter was greater in the exposed dentin matrix than in the matrix of the repair tissue (Fig. 5d). When the exposed dentin matrix was heavily obscured by electron-dense organic material, the large interfibrillar spaces were no longer discernible; gold particles seemed to be associated with the obscured matrix compartments (Fig. 5e). Collagen fibrils were present both between the dentin surface and the adjacent cells and in the dentinal tubules. Gold particles were also observed in the electron-dense peritubular dentin matrix (Fig. 5e, f). An advanced stage of the deposition of repair cementum matrix is illustrated in Fig. 6. Immunolabeling for BSP (Fig. 6a) and OPN (Fig. 6b) was seen (1) in association with mineralization foci adjacent to the mineralization front, (2) over the dentin matrix peripheral to the resorbed surface, and (3) both internal and external to the wall of the dentinal tubules. Gold particle densities diminished toward the deeper portion of the dentin matrix, i.e., away from both the resorbed surface and the periphery of the dentinal tubules.

\section{Discussion}

The use of two different antibodies against BSP and OPN, respectively, in the same study has allowed a direct comparison of their labeling results. All four antibodies yield essentially the same labeling pattern. Consistent with other studies (Riminucci et al. 1995; Bosshardt et al. 1998; Nanci 1999), immunolabeling for BSP and OPN is associated with the electron-dense regions of the extracellular matrix, viz., regions that are indicative of mineralized matrix and correspond to the dark matrix regions in decalcified sections that are stained by metachromatic dyes for light microscopy (Weinstock et al. 1972; Bosshardt and Schroeder 1991, 1994; McKee and Nanci 1993). The present study shows, for the first time, that the region of the established interface between the resorbed dentin and the repair cementum in human deciduous teeth is heavily labeled for both BSP and OPN. The sequential analysis has shown that (1) labeling for both BSP and OPN is first detectable in association with the exposed collagen fibrils of the resorbed dentin after the withdrawal of the odontoclast, (2) the collagenous matrix of the repair cementum becomes integrated in an electrondense zone that is labeled for both BSP and OPN, and (3) a wide, variably thick zone, that is labeled for both BSP and OPN, comprises, to a large extent, the underlying matrix of the peripheral dentin.

The basophilic electron-dense matrix found at the interfacial region between the resorbed dentin and repair cementum, which is referred to as the reversal line, is thought to represent a distinct interfacial layer with special functions (Sahara et al. 1993). At present, we cannot conclude that the reversal line contains molecules that trigger cementoblast differentiation (Sahara et al. 1993). Nevertheless, dentin matrix proteins exposed on or released from the resorbed dentin are known to induce cell differentiation and mineralized tissue formation (Bang and Urist 1967; Urist and Strates 1971; Somerman et al. 1987; Veis et al. 1989; Nebgen et al. 
1999; Silva et al. 2004). During the reversal phase of the bone remodeling cycle (Nanci 1999), a special class of mononuclear cells has been proposed to form the cement line in bone (Bosshardt and Schroeder 1994), a possible equivalent to the reversal line in teeth. However, the observation that calvarial osteoblasts in culture form a cementline-like matrix containing OPN (Nanci et al. 1996) does not support the concept that a special class of cells other than osteoblasts form such matrix layers. The involvement of cells in the synthesis of a particular protein by post-embedding immunocytochemistry may be difficult to determine, since the amount produced by a cell under normal conditions appears to be near the threshold of detectability (Nanci 1999). Nevertheless, protein labeling for BSP (present study; Bianco et al. 1993) and OPN (McKee and Nanci 1996c; McKee et al. 1996) in secretory granules of mineralized tissue-forming cells have occasionally been observed. Furthermore, from studies with other techniques, both cementoblasts and osteoblasts are known to synthesize and secrete BSP and OPN (Bosshardt et al. 1998; Nanci 1999). Other contributing sources such as blood plasma (Bautista et al. 1996; Seibel et al. 1996) and inflammatory cells (McKee and Nanci 1996a) must however also be taken into consideration (Bosshardt et al. 1998; VandenBos et al. 1999). There is no indication in the present study that odontoclasts synthesize and secrete BSP or OPN. This has, however, been proposed for odontoclasts (Sahara 1998) and osteoclasts (Merry et al. 1993; Connor et al. 1995; Dodds et al. 1995; Yamate et al. 1997). Based on the above studies and considerations, the initial deposition of BSP and OPN along the resorbed dentin surface is proposed as being part of the normal protein secretory sequence of cementoblasts that form repair cementum.

The reversal line in teeth, like the cement line in bone (McKee and Nanci 1996b), may exert an adhesive function (Sahara 1998; Yamamoto et al. 2000). The available data in the literature suggest that, with respect to formation, composition, and function, fundamental differences exist between the cement line in bone and the reversal line in teeth (Bosshardt and Schroeder 1994; Bosshardt et al. 1998; Nanci 1999). The resorbed bone matrix lacks extensive amounts of exposed (i.e., decalcified) collagen fibrils. This arrangement apparently results in a more planar accumulation of the cement line compared with the reversal line in teeth. Extensive interlacement of collagen fibrils may not be a desirable arrangement in bone, since the cement line must have both adhesive and ductile properties to allow force dissipation (Burr et al. 1988; McKee and Nanci 1996c; Bosshardt et al. 1998). The present study shows that BSP and OPN are co-distributed in both the peripheral dentin matrix and the proper interfacial region in which they fill the interfibrillar spaces. BSP (Fujisawa and Kuboki 1992; Fujisawa et al. 1995) and OPN (Gorski et al. 1995) have an affinity for collagen fibrils, and both proteins bind to hydroxyapatite crystals and may be involved in the regulation of mineralization (Goldberg et al. 2001). Our findings suggest that (1) BSP and OPN first occupy the most accessible matrix elements, and (2) odontoclasts precondition the peripheral dentin matrix such that it is capable of accommodating
NCPs such as BSP and OPN, two proteins that are normally found only in minute amounts in the dentin matrix (Butler et al. 2003). This high accumulation in the old dentin matrix apparently does not occur in the old bone matrix, suggesting that fundamental differences exist between either the resorptive activity of odontoclasts and osteoclasts or the matrices of dentin and bone. Both osteoclasts (Stenbeck 2002; Sasaki 2003) and odontoclasts (Sahara et al. 1994, 1996; Oshiro et al. 2001; Linsuwanont et al. 2002a,b) superficially dissolve the mineral crystals and proteolytically degrade the organic matrix. Molecules such as BSP and OPN may regulate the spread of mineral and accommodate it. The mineralization process may thus be regarded as a continuum, starting in the depth of the old dentin matrix and crossing over the interfacial region. The spread of mineral, the possible cohesive forces between NCPs, and the interdigitation of the collagen fibrils may all assist in forming a force-resistant union between dentin and cementum. Consistent with another study (Sahara 1998), the deposition of the collagen fibrils of the repair cementum occurs almost concomitantly with the deposition of organic material containing at least BSP and OPN among the exposed dentinal collagen fibrils. Interdigitation of collagen fibrils appears not to be as extensive as that found in other studies (Bosshardt and Schroeder 1994; Bosshardt et al. 1998), leaving large interfibrillar spaces that become filled with NCPs as repair cementum formation progresses. These observations are consistent with the known interfibrillar accumulation of BSP and OPN (Nanci 1999; Bosshardt and Nanci 2000) and explains the strong labeling at this site.

Tissue separation between the repair cementum and the treated root surface is a common observation in histological sections. Tissue processing for paraffin embedding, which produces severe shrinkage artifacts (Fletcher 1975; Litwin 1985; De Haan et al. 2002), is held responsible for tissue separation. Splits are, however, also observed in resin-embedded tissues, and split formation is associated with the presence of an interfacial electron-dense noncollagenous matrix layer (Listgarten 1972). Theoretically, the removal of hydroxyapatite during the histological decalcification process might weaken the interface. However, the presence of similar splits in undecalcified tissues (Nalbandian and Frank 1980) and the occurrence of cemental tears, which are associated with rapid periodontal breakdown (Leknes 1997; Marquam 2003), suggest that histological tissue processing may not necessarily be the reason for interfacial weakness. Furthermore, the detection of plaque bacteria and leukocytes in such tissue gaps in histological sections has provided clear evidence that gap formation can occur before tissue processing (Bosshardt et al. 2005). Thus, despite the fact that root surface conditioning aims at providing a suitable substrate for improved cell-matrix attachment and matrix-matrix adhesion following periodontal therapy (Lowenguth and Blieden 1993), interfacial strength after root demineralization shows variable results (Schroeder et al. 1992; MacNeil and Somerman 1999). The finding that tissue separation between repair cementum and the resorbed dentin is not observed in histological sections suggests that the odontoclasts precondition the root surface 
such that the newly deposited repair cementum is firmly attached to it. Future experimental studies aimed at improving periodontal regeneration should better mimic the natural root surface conditioning process.

Acknowledgements The authors are indebted to Mrs. M. Aeberhard for excellent technical assistance in the laboratory and to Dr. A. Lussi, Department of Operative, Preventive and Pediatric Dentistry, School of Dental Medicine University of Berne, Berne, Switzerland for providing some of the deciduous teeth included in the study.

\section{References}

Bang G, Urist MR (1967) Bone induction in excavation chambers in matrix of decalcified dentin. Arch Surg 94:781-789

Bautista DS, Saad Z, Chambers AF, Tonkin KS, O'Malley FP, Singhal H, Tokmakejian S, Bramwell V, Harris JF (1996) Quantification of osteopontin in human plasma with an ELISA: basal levels in pre- and postmenopausal women. Clin Biochem 29:231-239

Bendayan M (1995) Colloidal gold post-embedding immunocytochemistry. Prog Histochem Cytochem 29:1-159

Bendayan M, Zollinger M (1983) Ultrastructural localization of antigenic sites on osmium-fixed tissues applying the protein A-gold technique. J Histochem Cytochem 31:101-109

Bianco P, Riminucci M, Silvestrini G, Bonucci E, Termine JD, Fisher LW, Robey PG (1993) Localization of bone sialoprotein (BSP) to Golgi and post-Golgi secretory structures in osteoblasts and to discrete sites in early bone matrix. J Histochem Cytochem 41: 193-203

Blomlöf L, Lindskog S (1994) Quality of periodontal healing. II. Dynamics of reparative cementum formation. Swed Dent J 18:131-138

Bosshardt DD, Nanci A (2000) The pattern of expression of collagen determines the concentration and distribution of noncollagenous proteins along the forming root. In: Goldberg M, Boskey A, Robinson C (eds) Chemistry and biology of mineralized tissues. American Academy of Orthopaedic Surgeons, Vittel, France, pp 129-136

Bosshardt DD, Schroeder HE (1991) Initiation of acellular extrinsic fiber cementum on human teeth. A light- and electron-microscopic study. Cell Tissue Res 263:311-324

Bosshardt DD, Schroeder HE (1994) How repair cementum becomes attached to the resorbed roots of human permanent teeth. Acta Anat (Basel) 150:253-266

Bosshardt DD, Zalzal S, McKee MD, Nanci A (1998) Developmental appearance and distribution of bone sialoprotein and osteopontin in human and rat cementum. Anat Rec 250:13-33

Bosshardt DD, Sculean A, Windisch P, Pjetursson BE, Lang NP (2005) Effects of enamel matrix proteins on tissue formation along the roots of human teeth. J Periodontal Res 40:158-167

Burr DB, Schaffler MB, Frederickson RG (1988) Composition of the cement line and its possible mechanical role as a local interface in human compact bone. J Biomech 21:939-945

Butler WT, Brunn JC, Qin C (2003) Dentin extracellular matrix (ECM) proteins: comparison to bone ECM and contribution to dynamics of dentinogenesis. Connect Tissue Res 44 (Suppl 1):171-178

Connor JR, Dodds RA, James IE, Gowen M (1995) Human osteoclast and giant cell differentiation: the apparent switch from nonspecific esterase to tartrate resistant acid phosphatase activity coincides with the in situ expression of osteopontin mRNA. J Histochem Cytochem 43:1193-1201

De Haan BJ, Goor H van, De Vos P (2002) Processing of immunoisolated pancreatic islets: implications for histological analyses of hydrated tissue. Biotechniques 32:612-619

Dodds RA, Connor JR, James IE, Rykaczewski EL, Appelbaum E, Dul E, Gowen M (1995) Human osteoclasts, not osteoblasts, deposit osteopontin onto resorption surfaces: an in vitro and ex vivo study of remodeling bone. J Bone Miner Res 10:1666-1680
Fisher LW, Stubbs JT III, Young MF (1995) Antisera and cDNA probes to human and certain animal model bone matrix noncollagenous proteins. Acta Orthop Scand (Suppl) 266:61-65

Fletcher OJ (1975) Plastic embedding of avian tissues for diagnostic histopathology. Avian Dis 19:201-208

Fujisawa R, Kuboki Y (1992) Affinity of bone sialoprotein and several other bone and dentin acidic proteins to collagen fibrils. Calcif Tissue Int 51:438-442

Fujisawa R, Nodasaka Y, Kuboki Y (1995) Further characterization of interaction between bone sialoprotein (BSP) and collagen. Calcif Tissue Int 56:140-144

Goldberg HA, Warner KJ, Li MC, Hunter GK (2001) Binding of bone sialoprotein, osteopontin and synthetic polypeptides to hydroxyapatite. Connect Tissue Res 42:25-37

Gorski JP, Kremer E, Ruiz-Perez J, Wise GE, Artigues A (1995) Conformational analyses on soluble and surface bound osteopontin. Ann N Y Acad Sci 760:12-23

Kawaguchi H, Ogawa T, Kurihara H, Nanci A (2001) Immunodetection of noncollagenous matrix proteins during periodontal tissue regeneration. J Periodontal Res 36:205-213

Leknes KN (1997) The influence of anatomic and iatrogenic root surface characteristics on bacterial colonization and periodontal destruction: a review. J Periodontol 68:507-516

Linsuwanont B, Takagi Y, Ohya K, Shimokawa H (2002a) Localization of cathepsin $\mathrm{K}$ in bovine odontoclasts during deciduous tooth resorption. Calcif Tissue Int 70:127-133

Linsuwanont B, Takagi Y, Ohya K, Shimokawa H (2002b) Expression of matrix metalloproteinase- 9 mRNA and protein during deciduous tooth resorption in bovine odontoclasts. Bone 31 : 472-478

Listgarten MA (1972) Electron microscopic study of the junction between surgically denuded root surfaces and regenerated periodontal tissues. J Periodontal Res 7:68-90

Litwin JA (1985) Light microscopic histochemistry on plastic sections. Prog Histochem Cytochem 16:1-84

Lowenguth RA, Blieden TM (1993) Periodontal regeneration: root surface demineralization. Periodontol 2000 1:54-68

Luder HU, Zappa U (1998) Nature and attachment of cementum formed under guided conditions in human teeth. An electron microscopic study. J Periodontol 69:889-898

MacNeil RL, Somerman MJ (1999) Development and regeneration of the periodontium: parallels and contrasts. Periodontol 200019 : $8-20$

Marquam BJ (2003) Atypical localized deep pocket due to a cemental tear: case report. J Contemp Dent Pract 4:52-64

McKee MD, Nanci A (1993) Ultrastructural, cytochemical and immunocytochemical studies on bone and its interfaces. Cells Mater 3:219-243

McKee MD, Nanci A (1996a) Secretion of osteopontin by macrophages and its accumulation at tissue surfaces during wound healing in mineralized tissues: a potential requirement for macrophage adhesion and phagocytosis. Anat Rec 245:394-409

McKee MD, Nanci A (1996b) Osteopontin at mineralized tissue interfaces in bone, teeth, and osseointegrated implants: ultrastructural distribution and implications for mineralized tissue formation, turnover, and repair. Microsc Res Tech 33:141-164

McKee MD, Nanci A (1996c) Osteopontin: an interfacial extracellular matrix protein in mineralized tissues. Connect Tissue Res 35:197-205

McKee MD, Zalzal S, Nanci A (1996) Extracellular matrix in tooth cementum and mantle dentin: localization of osteopontin and other noncollagenous proteins, plasma proteins, and glycoconjugates by electron microscopy. Anat Rec 245:293-312

Merry K, Dodds R, Littlewood A, Gowen M (1993) Expression of osteopontin mRNA by osteoclasts and osteoblasts in modelling adult human bone. J Cell Sci 104:1013-1020

Nalbandian J, Frank RM (1980) Electron microscopic study of the regeneration of cementum and periodontal connective tissue attachment in the cat. J Periodontal Res 15:71-89

Nanci A (1999) Content and distribution of noncollagenous matrix proteins in bone and cementum: relationship to speed of formation and collagen packing density. J Struct Biol 126:256-269 
Nanci A, Zalzal S, Gotoh Y, McKee MD (1996) Ultrastructural characterization and immunolocalization of osteopontin in rat calvarial osteoblast primary cultures. Microsc Res Tech 33:214231

Nebgen DR, Inoue H, Sabsay B, Wei K, Ho CS, Veis A (1999) Identification of the chondrogenic-inducing activity from bovine dentin (bCIA) as a low-molecular-mass amelogenin polypeptide. J Dent Res 78:1484-1494

Neiss WF (1984) Electron staining of the cell surface coat by osmiumlow ferrocyanide. Histochemistry 80:231-242

Oshiro T, Shibasaki Y, Martin TJ, Sasaki T (2001) Immunolocalization of vacuolar-type $\mathrm{H}^{+}$-ATPase, cathepsin $\mathrm{K}$, matrix metalloproteinase-9, and receptor activator of NFkappaB ligand in odontoclasts during physiological root resorption of human deciduous teeth. Anat Rec 264:305-311

Reynolds JJ, Meikle MC (1997) Mechanisms of connective tissue matrix destruction in periodontitis. Periodontol 2000 14:144157

Riminucci M, Silvestrini G, Bonucci E, Fisher LW, Gehron Robey P, Bianco P (1995) The anatomy of bone sialoprotein immunoreactive sites in bone as revealed by combined ultrastructural histochemistry and immunohistochemistry. Calcif Tissue Int 57:277-284

Sahara N (1998) Resorption and repair of human deciduous teeth prior to shedding. Devidovitch Z, Mah J (eds) Biological mechanisms of tooth eruption, resorption and replacement by implants. International Conference, Toledo, Spain. EBSCO Media, Birmingham

Sahara N, Okafuji N, Toyoki A, Ashizawa Y, Deguchi T, Suzuki K (1993) Cementum-like tissue deposition on the resorbed pulp chamber wall of human deciduous teeth prior to shedding. Acta Anat (Basel) 147:24-34

Sahara N, Okafuji N, Toyoki A, Ashizawa Y, Deguchi T, Suzuki K (1994) Odontoclastic resorption of the superficial nonmineralized layer of predentine in the shedding of human deciduous teeth. Cell Tissue Res 277:19-26

Sahara N, Toyoki A, Ashizawa Y, Deguchi T, Suzuki K (1996) Cytodifferentiation of the odontoclast prior to the shedding of human deciduous teeth: an ultrastructural and cytochemical study. Anat Rec 244:33-49

Sasaki T (2003) Differentiation and functions of osteoclasts and odontoclasts in mineralized tissue resorption. Microsc Res Tech 61:483-495

Schroeder HE (1992) Biological problems of regenerative cementogenesis: synthesis and attachment of collagenous matrices on growing and established root surfaces. Int Rev Cytol 142:1-59
Schroeder HE, Luder HU, Bosshardt DD (1992) Morphological and labeling evidence supporting and extending a modern theory of tooth eruption. Schweiz Monatsschr Zahnmed 102:20-31

Sculean A, Donos N, Windisch P, Brecx M, Gera I, Reich E, Karring $T$ (1999) Healing of human intrabony defects following treatment with enamel matrix proteins or guided tissue regeneration. J Periodontal Res 34:310-322

Seibel MJ, Woitge HW, Pecherstorfer M, Karmatschek M, Horn E, Ludwig H, Armbruster FP, Ziegler R (1996) Serum immunoreactive bone sialoprotein as a new marker of bone turnover in metabolic and malignant bone disease. J Clin Endocrinol Metab 81:3289-3294

Silva TA, Rosa AL, Lara VS (2004) Dentin matrix proteins and soluble factors: intrinsic regulatory signals for healing and resorption of dental and periodontal tissues? Oral Dis 10:63-74

Somerman MJ, Nathanson MA, Sauk JJ, Manson B (1987) Human dentin matrix induces cartilage formation in vitro by mesenchymal cells derived from embryonic muscle. J Dent Res 66:1551-1558

Stenbeck G (2002) Formation and function of the ruffled border in osteoclasts. Semin Cell Dev Biol 13:285-292

Urist MR, Strates BS (1971) Bone morphogenetic protein. J Dent Res 50:1392-1406

VandenBos T, Bronckers AL, Goldberg HA, Beertsen W (1999) Blood circulation as source for osteopontin in acellular extrinsic fiber cementum and other mineralizing tissues. J Dent Res 78:1688-1695

Veis A, Sires B, Clohisy J (1989) A search for the osteogenic factor in dentin. Rat incisor dentin contains a factor stimulating rat muscle cells in vitro to incorporate sulfate into an altered proteoglycan. Connect Tissue Res 23:137-144

Warshawsky H, Moore G (1967) A technique for the fixation and decalcification of rat incisors for electron microscopy. J Histochem Cytochem 15:542-549

Weinstock A, Weinstock M, Leblond CP (1972) Autoradiographic detection of $3 \mathrm{H}$-fucose incorporation into glycoprotein by odontoblasts and its deposition at the site of the calcification front in dentin. Calcif Tissue Res 8:181-189

Yamamoto T, Domon T, Takahashi S, Suzuki R, Islam MN (2000) The fibrillar structure of cement lines on resorbed root surfaces of human teeth. J Periodontal Res 35:208-213

Yamate T, Mocharla H, Taguchi Y, Igietseme JU, Manolagas SC, Abe E (1997) Osteopontin expression by osteoclast and osteoblast progenitors in the murine bone marrow: demonstration of its requirement for osteoclastogenesis and its increase after ovariectomy. Endocrinology 138:3047-3055 